\title{
O CUIDADO DE SI DO IDOSO COMO INSTRUMENTO DE TRABALHO NO PROCESSO DE CUIDAR
}

[The elders' self care as a work instrument in the caring process]

[El cuidado de sí mismo del anciano como instrumento del trabajo en proceso de cuidar]

\author{
M aria Helena Lenardt* \\ Débora O. Michal tuch** \\ Tatiane Prette K uznier*** \\ Vanessa L uz dos Santos****
}

\begin{abstract}
RESUM O: Estudo etnográfico sobre o cuidado de si de idosos numa unidade de internação cirúrgica e no domicílio. Os dados em campo foram col etados de agosto de 2002 a março de 2003, por meio da observação participante e de entrevistas etnográficas fundamentadas em Spradley. 0 objetivo deste estudo foi: conhecer como o doente idoso cirúrgico cuida de si durante a internação em uma unidade cirúrgica e no pós-operatório domiciliar. Os domínios identificados foram cinco. 0 tema emergido da descrição etnográfica foi: o cuidado de si do idoso, teias de significados que ele mesmo teceu.
\end{abstract}

PALAVRAS-CHAVE: Cuidados de enfermagem; Idoso; Cuidado; Cultura.

\section{IINTRODUÇÃO}

No Paraná, segundo estimativa do Instituto Paranaense de Desenvolvimento Econômico e Social IPA RDES (1), em 2005, de um total de 10.043.918 habitantes, 882.262 apresentam 60 anos ou mais, o que significa $8,78 \%$ da população paranaense.

Em Curitiba, de um total de 1.587 .315 habitantes em 2000, 133.619 pessoas eram maiores de 60 anos, o que representa $8,35 \%$ do total de habitantes ${ }^{(2)}$. Portanto, o número de idosos com 60 anos ou mais cresce em Curitiba, de forma a aumentar, proporcional mente, a quantidade de

\footnotetext{
* Enfermeira. Doutora em Filosofia da Enfermagem pela UFSC. Professora Sênior e Coordenadora do G rupo M ultiprofissional de Pesquisa sobre Idosos do Programa de Pós-Graduação em Enfermagem da Univesidade Federal do Paraná.

**Enfermeira graduada pela UFPR, pós-graduanda em Saúde Pública FADEP.

***Enfermeira do Hospital Evangélico de Curitiba. M estranda em Enfermagem UFPR.

****Enfermeira do Hospital Infantil Pequeno Príncipe em Curitiba. M estranda em Enfermagem UFPR.
}

idosos dentro da população curitibana e mundial ${ }^{(2)}$. Nos próximos 20 anos, a população idosa do B rasil poderá ultrapassar os 30 milhões de pessoas e deverá representar quase $13 \%$ da população ao final deste período (2).

N este contexto de rápido crescimento da população idosa brasileira, mais rapidamente do que em muitos países desenvolvidos surgem as características de se envelhecer em meio à condição social e econômica desfavorável, que gera circunstâncias que fazem o processo de envelhecimento muito mais complicado que em outras áreas do mundo.

Essas condições conduzem o processo de envelhecimento não só por uma velocidade súbita, mas também por uma grande demanda potencial por serviços de saúde. 0 processo de envelhecimento nos países desenvolvidos ocorreu ${ }^{(3)}$ muito tempo depois de eles terem adquirido padrões el evados de vida, reduzido desigualdades sociais e econômicas e implementado um número de estratégias institucionais para compensar os efeitos das desigualdades, ao menos na área de acesso aos serviços de saúde.

0 processo de envelhecimento (4) associa-se a um aumento dos riscos de incidência de inúmeras doenças, quer pelo próprio processo biológico, quer pelos longos períodos de exposição a agentes patógenos. A maior incidência e prevalência de eventos mórbidos nos idosos resultam em uma demanda relativamente maior dos serviços de saúde com maior número de consultas, maior tempo médio de internação, que tem por conseqüência a exigência de maior e melhor assistência nos cuidados prestados e principalmente nas orientações de cuidados pelos profissionais de enfermagem.

As orientações de cuidado fornecidas pelos profissionais que acompanham os idosos hospitalizados para tratamento cirúrgico freqüentemente afiguram somente práticas de cuidados aprendidos na academia e, portanto, considerados de cunho científico, e isto nos faz refletir e ques- 
tionar até que ponto essa característica das orientações dos cuidados atinge positivamente os doentes. $N$ ão podemosponder às questões de cuidados referentes aos doentes idosos somente com nossos próprios conceitos e percepções, é preciso introduzir também a visão deles.

A creditamos que ao cuidar do doente idoso cirúrgico no hospital e no domicílio, empregando meios que permitam levar em consideração a complexidade e a inteireza de sua vida, estaremos ajudando-o a atravessar o percurso dos sofrimentos no pré, trans e pós-operatório com menor sofrimento.

Para isso é preciso descer aos detalhes, além das etiquetas enganadoras, além dos tipos metafísicos, além das similaridades vazias, para apreender corretamente o caráter essencial não apenas das várias culturas, mas também dos vários tipos de indivíduos dentro de cada cultura ${ }^{(5)}$.

A enfermagem precisa conhecer os modos como a pessoa idosa se cuida, ajudar o doente a ser mais ele, pois a sabedoria popular ${ }^{(6)}$ tem frequentemente exprimido a importância da imaginação para a própria saúde do indivíduo para o equilíbrio e riqueza da sua vida interior.

0 idoso apresenta restrição em aceitar o que lhe é imposto e o que é real izado por ele, mas demonstra interesse em praticar o seu cuidado embasado em seus princípios culturais. Diante desse enfoque para o cuidado e o propósito no cuidado de si colocamos nesta pesquisa o seguinte objetivo: conhecer como o doente idoso cirúrgico cuida de si durante a internação em unidade cirúrgica e no pós-operatório domiciliar.

\section{METODOLOGIA}

Para a realização da pesquisa foram participantes idosos de ambos os sexos, sendo que idoso, segundo a Política Nacional do Idoso (7), é o que conta igual ou mais de 60 anos.

Utilizamos 0 método etnográfico ${ }^{(8,9,10)}$ de cunho interpretativo ${ }^{(11,5,12,13)}$. Para a coleta das informações desenvolvemos a observação-participante e a entrevista etnográfica ${ }^{(8,9)}$ durante o período da internação cirúrgica e alta hospitalar no domicílio dos idosos.

A s informações foram coletadas na instituição hospital ar e no domicílio, no período de agosto de 2002 a março de 2003, suficiente para adquirir a saturação dos domínios.

A participação no cenário hospitalar ocorreu por meio dos cuidados de enfermagem prestados ao paciente idoso no pós-operatório, como: al imentação, real ização de curativos, higiene oral, corporal e orientações de cuidado. A participação no cenário domiciliar do idoso teve como instrumentos facilitadores do processo de interação a verificação da pressão arterial, realização de curativos e/ou outros procedimentos de enfermagem.

No questionamento etnográfico adotamos a forma de um diálogo coloquial de forma conjunta com a observação participante, alicerçada na questão: Como o sr (srâ) se cuida? Seguimos os três ti pos de questões para a entrevista etnográfica: as questões descritivas, as questões estruturais e as questões contraste ${ }^{(10)}$.

As questões descritivas foram utilizadas na fase da observação descritiva, focalizada e seletiva. Seu objetivo foi expandir a explicação dos participantes constituindo-se na base da entrevista, o que permite o conhecimento do modo como os idosos vêem o cuidado de si.

As questões estruturais permitiram compreender como os idosos organizam o que sabem a respeito do cuidado de si. Elas complementaram e ampliaram os dados descritivos e permitiram o conhecimento da organização sistemática da cultura de cuidados. Foram utilizadas também as questões contraste que tiveram a final idade de comparar as diferenças e foram formuladas quando percebíamos as diferenças culturais, à medida que o idoso descrevia os símbolos de cuidado.

A análise dos dados culturais foi iniciada concomitantemente à coleta de informações que foram registradas em diário de campo. Efetivamos análises de domínios, taxonômicas e temáticas ${ }^{(9)}$.

Foram respeitados os preceitos éticos de participação voluntária, esclarecida e consentida segundo Resolução 196/96 ${ }^{(14)}$ através do preenchimento da ficha de consentimento pelo idoso. Os idosos que fizeram parte do estudo, a partir das observações e questionamentos foram consultados e esclarecidos. Foi garantido o direito de desistirem da participação e esclarecido quanto ao sigilo das informações prestadas, assim como o completo anonimato.

\section{RESULTADOS}

Neste artigo apresentamos os domínios sucintamente, em recortes de discurso dos idosos. A apresentação dos resultados das análises de domínios e taxonomias na forma de quadros ${ }^{\left({ }^{9}\right)}$ será omitida e mostrada na linguagem discursiva e descritiva em virtude da dimensão do espaço que dispomos para a publicação.

Domínio Cultural 1 - Gêneros alimentícios como significantes terapêuticos

Os simbolismos dos alimentos estão enraizados e presentes no dia-a-dia dos idosos, fazem parte do sistema de conhecimento deles, advindos da bagagem sócio-cultural.

Para os idosos hospitalizados os hábitos alimentares são preservados por meio dos alimentos ingeridos em 
seu cotidiano, trazidos por eles ou por seus familiares, 0 que é uma forma de se sentirem em "casa" nesta trajetória. Porém, nesse local os al imentos são mais controlados pela equipe de enfermagem, o que não ocorre em domicílio. Quando o idoso está em sua casa, no pós-operatório, longe das imposições real izadas pelos profissionais de saúde, fica livre para fazer suas escolhas referentes ao cuidado de si. Comem o que desejam e freqüentemente não seguem as orientações a cerca dos al imentos. Para os idosos, as representações simbólicas referentes aos alimentos que consideram "bons" para o período pós-operatório diferem, em grande parte, daquel as indicadas pelos profissionais de saúde:

“E u adoro mamão, me faz bem. Abacaxi eu não gosto, não me faz bem, é picante, tem muito ácido. 0 mamão segura 0 intestino" (M.S.A., 72 anos).

"M inha filha falou para eu tomar uma colher de mel todos os dias em jejum, é bom para os problemas do pâncreas" (J.A.B., 69 anos).

Os alimentos proibitivos e os indicados pelos profissionais de saúde, somente são incorporados no cotidiano do idoso quando ele adquiriu identidade simbólica para a necessidade do uso ou da proibição. A estrutura desta identidade para os alimentos está alicerçada principal mente na família e vizinhos. Dificilmente a ordem prescrita pel os profissionais é assimilada pelo idoso no momento da consulta ou nas orientações para a al ta, principalmente quando estas não fazem parte dos significados que estruturam a compreensão do que é a dieta "boa" e o cuidar-se "bem":

"Eu gosto de leite aquele vindo da vaca, não o do mercado porque parte do leite é remédio. É bom para curar 0 estômago e fortalece o coração" (A.S., 67 anos).

De um modo geral, em casa ou no hospital o alimento desempenha diversas funções no cotidiano dos idosos, classificados como bons/ruins, fortes/fracos, magros/ gordos, frios/quentes, sujos/limpos e al gumas vezes considerados como remédios.

Os alimentos classificados bons/ruins podem ser identificados nos seguintes recortes:

"Leite com açúcar e iogurte é bom tomar à noite para dormir" (J.A.B., 69 anos).

"Chá de couve para quando sinto dor. Tomo café sem açúcar ou adoçante por causa do diabete e do estômago. Tomo Sustagem, é bom para a fraqueza, estou magra" (M.F.P., 73 anos).

"Evito doces por causa da pressão e do diabetes" (H.S., 71 anos).
"Não como banana porque tem muito ácido e a banana e maçã causam disenteria" (R.C.L., 67 anos).

"Não como repolho e ovo porque dá gazes, o feijão que é bom" (A.S., 67 anos).

"A carne que eu gosto é a de gado, porque 0 gado não come tudo azedo, como o porco e a galinha. 0 gado come o verde da plantação. A carne de boi é limpa, ele só come coisas limpas. $\mathrm{Na}$ hora de comer a carne de porco me parece que embrulha tudo, porque ele come um monte de porcaria. E tem as doenças, aquele verme que tem no porco, o boi é mais difícil ter o verme, ele é uma carne mais sadia" (J.C., 73 anos).

"Para a gripe o alho é bom, de cada três meses um grãozinho cru, cortado bem fininho para comer na janta, 0 alho tira de dentro para fora é quente solta o catarro, não recolhe é um grande remédio, só não pode ir para fora depois" (J.A.B., 69 anos).

A maioria dos idosos considera os alimentos como significantes de cura, portanto tornam-se verdadeiros remédios em suas vidas. A lguns idosos do estudo apresentava doença como o Diabete M el litus e a hipertensão, porém não tinha noção dos alimentos que se ingeridos poderiam provocar agravos a sua doença.

Os alimentos podem ser utilizados como remédio, [...]: dietas especiais podem ser consideradas como uma forma de medicação para determinadas doenças ou estados psicológi$\cos { }^{(15: 55)}$.

Para os idosos pesquisados alguns al imentos também foram considerados como verdadeiros venenos e banidos de suas dietas. A ingestão de determinados al imentos combinados acreditam que podem provocar distúrbios ou melhora na saúde/doença, assim como o "veneno" e ou "puro remédio" para a sua saúde. Por vezes, apontam associações de alimentos que consideram "puro veneno," as quais não encontramos comprovação científica.

A gordura animal ainda é vista por muitos dos participantes como um bom al imento, pelo sabor que oferece e sustento para o corpo. Como exemplificamos a seguir:

"Eu gosto de comida gorda, porque era assim quando eu morava no sítio, já é costume. Ela fortifica quem está fraco, a comida aqui do hospital é puro veneno, não tem gosto, deixa fraco" (J.C., 73 anos).

"A banha da carne é quente, forte, fortifica o corpo. Agora, não se pode comer carne de porco com fruta, solta 0 intestino e daí pode até morrer" (H.S., 71 anos).

"A gordura da carne é que sustenta, junto com vinho da colônia cura qualquer coisa" ( M. S., 72 anos). 
Domínio Cultural 2 - A tividades de lazer: hábitos para passar o tempo

0 envel hecimento traz mudanças biológicas, psicológicas e sociais para os indivíduos alterando as relações destes com o meio no qual estão inseridos. Estas modificações ocorrem principalmente na esfera social devido à chegada da aposentadoria.

Instituída a aposentadoria na vida do idoso, o período de tempo livre deste aumenta significativamente, e poderá ser preenchido com o lazer que é definido segundo ${ }^{(16)}$ o tempo que cada um tem para si. Representa o conjunto de ocupações não obrigatórias às quais o indivíduo pode-se entregar de bom grado, seja para repousar, para se divertir, para desenvolver sua informação ou formação desinteressada, depois de liberado de suas obrigações profissionais, familiares e sociais. Como citado nos recortes de discurso abaixo, nos quais os idosos colocam o lazer como benefício:

"Ando na rua para bater papo e também por saúde, por causa do colesterol, coração e pressão" (J.C., 73 anos). "O tricô me salva é tricô e tricô o dia todo" (C.R., 69 anos).

"Converso com os amigos devido ao carinho que me dão. Caminho para melhorar tudo e distrair. Assisto a oração do pastor pela TV porque é importante, ajuda a ficar meIhor e a viver. Escuto música porque não gosto de ouvir besteiras" (M .J.S., 66 anos).

0 lazer para o idoso torna-se cada vez mais restrito devido às adversidades que este encontra na sociedade como: a carência de recursos financeiros os quais dificultam 0 acesso ao teatro, cinema, leitura e a outros bens culturais. A ssim como o trânsito dos idosos pela cidade fica prejudicado, em razão das irregularidades dos calçamentos das ruas e das grandes distâncias da moradia aos espaços de lazer, limitando-se na maioria das vezes ao espaço familiar, onde ficam restritos ao fazer,

inclui atividades que vão desde os cuidados pessoais (higiene), passando pelas as atividades da vida diária - comer, vestir, locomoção, comunicação -, até as atividades da vida prática - tel efonar, fazer compras [...] $]^{(17: 99)}$.

A situação de restrição ao lar e ao fazer éidentificada com os discursos abaixo:

“Não posso sair sozinho e a minha filha já gasta comigo até pra me levar no posto. Já teve vezes que emprestou a passagem do vizinho" (R.C.L., 67 anos).

"A minha atividade de lazer agora é lavar louça, fico fa- zendo qualquer coisa, já estou acostumada a ficar "de varde" , ficar tranqüila, o dinheiro é curto. Gosto de cuidar da casa, distrai a gente" (A.S., 67 anos).

"Ficar sentado e lavar uma loucinha é o que me distrai, já caí na rua, minha perna entrou num buraco e fiquei de cama meses, melhor é distrair em casa" (H.S. 71 anos).

Para o idoso é um desafio como ocupar seu tempo livre gerado pel as condições impostas pel o processo de envel hecimento, pela inadequação de acesso das vias públicas e pela baixa remuneração da aposentadoria. A sociedade brasileira não prepara o adulto e não está preparada para o lazer na velhice, visto que os adultos desenvolvem hábitos de lazer que mais tarde não condizem com a idade avançada.

0 cuidar de si que diz respeito ao lazer é realizado pelo idoso motivado para al guma finalidade. Para os idosos pesquisados, assim como o trabal ho, o lazer deve apresentar um "produto", e/ou "serviço". Os recortes de discurso a seguir demonstram tal situação:

"Dou um passeio no centro, dou uma volta na pracinha, sento e converso com as pessoas, uma boa conversa faz um bem para gente [...] alguma coisa que eu não sei eu acabo aprendendo" (M.S.A., 72 anos).

"Visito as filhas porque é em uma cidade calma e tem sítio, é lá que estão os meus netos e consigo trabalhar e fazer alguma coisa por eles, a gente não pode ser estorvo, não fazer nada" (J.A.B., 69 anos).

"As tarefas da casa distraem e não gosto de nada sujo, gosto de tudo limpinho faz bem para mim, ver tudo limpo, isto pra mim é lazer" (A.P.S., 78 anos).

0 hábito da leitura como lazer não foi encontrado nos idosos pesquisados. A creditamos que a faixa de escolaridade dê conta de explicar esta situação, visto que 83\% dos participantes não possuíam o ensino fundamental completo e a maioria deles, $58 \%$, eram analfabetos. 0 hábito da leitura também requer melhores condições financeiras daquela que encontramos nos idosos.

As principais atividades consideradas de lazer foram observadas com mais freqüência no domicílio do idoso, porém a nível hospitalar ele também preserva seus hábitos e realiza al guma atividade para o lazer, sempre com alguma intenção:

"Tricô faz bem e ajuda a passar o tempo e a dor, não penso assim na cirurgia" (C.R., 69 anos).

"Adoro fazer brincadeiras no hospital, como me maquiar, trouxe todas as minhas coisas para parecer que é minha casa, aqui já é tudo feio" (A.S., 67 anos).

"Ah, eu caminho pelo corredor, para fazer amigos, vou lá 
na frente, depois vou assistir TV na primeira enfermaria junto com outra mocinha que eu conheci, caminhar é bom, porque ficar só deitada o dia inteiro é ruim, cansa muito" (M.S.A., 72 anos).

Domínio Cultural 3 - A higiene pessoal: evidências de sujidade

Todas as pessoas possuem hábitos de higiene distintos que aprenderam a partir dos sistemas de conhecimento no qual estão inseridos ao longo da vida. Para os idosos participantes da pesquisa, higiene foi considerada: lavar 0 rosto, tomar banho, escovar os dentes e cuidados relacionados com a ferida cirúrgica. 0 mais valorizado dentre estes foi o banho, seja ele realizado com a ajuda de acompanhante, geralmente familiares (filhos) ou quando o idoso realiza esta tarefa sozinho, mas nem sempre este momento é tranqüilo, ele pode ser fonte de estresse para o idoso.

No período pós-cirúrgico, o idoso demonstrou significativa preocupação com a ferida cirúrgica e possibilidades de quedas no banheiro. Segundo estudo realizado ${ }^{(18)}$, os acidentes de quedas no ambiente domiciliar são freqüentes, especificamente no banheiro $(25,64 \%)$, em relação aos outros locais do domicílio perde apenas para a cozinha (42,59\%). Os discursos a seguir demonstram tal situação:

"M inha filha vai comigo tomar banho, esses dias eu caí no Box agora ela fica me cuidando para não acontecer de novo" (A.P.S., 78 anos).

"Tenho medo de cair por isto não lavo sempre a cabeça, fico tonto, já caí e agora com o corte da cirurgia é pior..." (J.C., 73 anos).

A simbologia do que é sujo, para os idosos está no odor, no corpo que exal a al gum cheiro desagradável. A freqüência e horários que realizam este cuidado no domicílio e no hospital são aspectos importantes a serem considerados. No hospital, acabam adaptando-se à rotina diária do banho, porém quando deixados sozinhos no banheiro lavam apenas os rostos e mol ham os cabel os para penteá-los. Em casa, a necessidade da higiene varia de acordo com a atividade que desempenham e temperatura do ambiente:

"Tomo banho quase todo dia, não precisa todo dia, algumas pessoas precisam porque cheiram mal e o meu corpo não cheira mal" (J.C., 73 anos).

"Tomo banho de corpo inteiro, para lavar a cabeça lavo de tarde que está quente 0 sol, lavo dia sim dia não, no frio não lavo para não pegar gripe" (A.S., 67 anos).

"Não vou mais para a roça, então não preciso tomar todo dia, lavo bem o pescoço e o rosto, refresca" (J.A.B., 69 anos).
Para al guns idosos participantes da pesquisa o banho traz sensação refrescante, boa aparência e conforto, considerado como forma de "remédio" para a ferida cirúrgica, para outros, é veneno, faz mal:

"Tomo banho todo dia, não posso ficar sem tomar banho, me agonia, quando tomo banho parece que sarou tudo" (A.P.S., 78 anos).

"Tomo banho com água morna para não queimar o local da cirurgia. Enquanto tenho essa ferida não posso molhar, a água aqui é veneno, abre e aí a desgraça tá feita. Quando a gente está doente, fica só na cama e não deve molhar o corpo, ele está quente debaixo da coberta, é perigoso, lavo o rosto" (J.C., 73 anos).

0 hábito de higiene dentária é pouco citado, o que importa é a aparência. Os dentes só devem ser limpos quando a sujeira é visível:

"Escovo os dentes só duas vezes por semana, agora eu não como carne, nem gruda nos dentes" . (H.S., 71 anos) "Tenho dentadura o que cheira mal é o dente natural" (M.S.A. 72 anos).

"Escovo os dentes quando como carne porque fica sujo. Não cheiro mal na boca, também já tenho pouco dente" (M .J.S., 66 anos).

Domínio Cultural 4 - Crenças ter apêuticas e religiosas: fontes simbólicas de apoio

Quando as pessoas adoecem procuram diversas alternativas de tratamento para curar-se. A experiência familiar da doença determina em parte a escolha da assistência, na maioria dos casos a assistência profissional é o último recurso a ser procurado. Esteé um fato observado com muita freqüência principalmente nos idosos.

0 doente apresenta um itinerário terapêutico sob a perspectiva de sistema de saúde, formado por três setores, 0 que 0 autor denomina sistema de cuidado à saúde ${ }^{(19)}$.

Esse sistema é formado pela interação de três setores: o profissional, caracterizado por profissões de cura organizadas, biomedicina, homeopatia, medicina chinesa; o folclórico, formado por especialistas de cura, porém sem regulamentação oficial, como curandei ros uso de ervas; e o popular ou familiar, onde estão representadas as famílias, amigos e vizinhos próximos do doente.

É o setor familiar ou popular que mais se envolve no contexto da doença e do cuidado ${ }^{(19)}$. Os relatos seguintes ilustram este fato:

"Começou a me doer o estômago, a minha comadre mandou tomar Oliva e isto me curou, é natural" (C.R., 69 anos). 
"M eu irmão teve doença da friagem, evito friagens porque pode atingir a próstata" (J.C. 73anos).

"Passo sal nas queimaduras, 0 sal não deixa criar bolhas, minha mãe já fazia" (A.S., 67 anos).

"Tomo chá de erva-doce porque é digestivo, chá de couve para aliviar a dor, chá de camomila porque é antibiótico; leite com açúcar e iogurte de pêssego é bom para dormir, líquidos para melhorar a irritação da garganta e chá de melissa e insulina da horta porque o médico de erva ensinou" (R.C.L., 67 anos).

"Lá em casa, aqui faz falta, como a casca do ovo caipira porque cura o osteoporose" (M.F.P., 73 anos).

"Q uando vem a dor forte e mais vezes é melhor procurar 0 médico, custa caro, sou de longe..." (J. C., 73 anos).

0 setor popular e o folclórico são os mais buscados pelos idosos justificados por ser natural e de baixo custo. A explicação do profissional a respeito da doença nem sempre está de acordo com o que o idoso acredita e utiliza no cuidado de si. De acordo com a identificação de sua enfermidade, o idoso define o setor de cuidado à saúde no qual irá inserir-se. Quando a doença não é curada por meio de chás medicinais ou rituais realizados por curandeiros, então a doença é considerada muito grave e um profissional da saúde é consul tado. Esta situação foi descrita no seguinte relato:

"Em casa eu tomava chá de quebra-pedra, mas isto serviu de lição porque quando a gente sente dor, tem que ir ao médico, chá só serve para infecçãozinha, friagem, para coisa grande não adianta" (J.A.B., 69 anos).

"Sempre curei tudo com remédio lá de casa, agora acho que é doença brava, aquela..." (J.C., 73 anos).

0 setor folclórico é constantemente referido como significante terapêutico e segundo ${ }^{(20)}$ é uma prática das pessoas idosas, como preventivo dos agravos das doenças respiratórias, reumatismos e outros males crônicos, resguardar-se do vento, chuva e friagem. Este significado terapêutico é identificado no discurso a seguir:

"Vou ficar mais na cama porque se eu facilitar, esfria os meus pés e eu fiz muita inalação e é um perigo pra pegar gripe" (J.C., 73 anos).

"Não engulo a semente da uva por causa do estômago, se a semente cai no estômago eu podia vomitar ou tossir e forçar a cirurgia" (M .J.S., 66 anos).

"D esencosto da cadeira, assim desencosto o pulmão e melhoro a respiração" (H.S., 71 anos).

Os significantes religiosos também são constantes durante o período de doença ou de convalescença. São um ponto de apoio para o doente que não encontra razões e maneiras de entender a situação que está vivendo. "Os modelos religiosos ${ }^{(21)}$ são transformados em imagens e práticas que possi bilitam resignificação da experiência do doente". A seguir recortes dos discursos dos idosos:

"Q uando sentia dor rezava, para acalmar a dor que era horrível" (M.J.S. 66 anos).

"Ajuda eu ficar melhor para viver, a oração é que me ajudou" (J.A.B. 69 anos).

"Acredito em orações é importante e me faz proveito, ajuda a ficar melhor para viver, eu cheguei no hospital ruim e a oração é que me ajudou" (J.C., 73 anos).

"Rezo quando sinto dor para acalmar a dor" (R.C.L., 67 anos).

No ambiente hospitalar os idosos mantêm seus hábitos religiosos:

"Vou na missa do hospital, porque é importante para a passagem do mal para o bem, descarrega" (J.A.B., 69 anos).

"Nuna me separo da bíblia" (M .J.S., 66 anos).

"D entro do armário tem um santinho, sempre levo comigo" (A.S., 67 anos).

Domínio Cultural 5 - Cuidados com a ferida cirúrgica: práticas populares compor tamentais de cuidado e nãocuidado

Observamos que no momento da al ta hospitalar, 0 paciente cirúrgico recebe orientações dos profissionais de enfermagem, sobre cuidados com a ferida cirúrgica, que são de fácil execução e geral mente estão ao al cance de todos os pacientes, quando relacionados às dificuldades de compreensão e de carência de recursos financeiros.

A orientação principal está relacionada ao uso de água e sabão na ferida cirúrgica, no entanto, os idosos assumem estes cuidados apenas quando encontram um significado no sistema de conhecimento deles, caso contrário utilizam o que consideram melhor, por não acreditarem na orientação e por medo de "prejudicarem" a cirurgia. Como nos discursos citados:

"Passo um pano na cirurgia porque não lavo os pontos com água e sabão" (H.S.,71anos).

"Lavo a cirurgia com água e sabão, eu passava mercúrio e metiolat, depois que passei água e sabão, acredito que não precisa passar mais nada" (M.S.A., 72 anos).

"Passo aquele chá ali, de marcela, minha filha quem fez, é bom" (M.F.P., 73 anos).

"Tenho medo de molhar a cirurgia, tomo banho de paninho 
molhado, o médico disse que era para lavar bem, mas eu tenho medo de molhar a cirurgia" (J .A.B., 69 anos).

No grupo de idosos pesquisados os cuidados com a ferida cirúrgica são guiados predominantemente por meio das práticas populares, ou seja, esses cuidados, na maioria, diferem das orientações realizadas pelas enfermeiras para a alta hospitalar. As práticas populares são legitimadas, inseridas no contexto cultural do qual o idoso faz parte. Essas práticas fazem parte do senso comum e geralmente não são questionadas, apenas acreditadas:

"O médico falou que não precisa passar nada, mas começou a ficar vermelho e passei uma pomada e foi boa, minha mulher falou para eu passar" (J.C., 73 anos).

"Quando coçava passava álcool passava para aliviar a coceira e funciona, passei para queimar este bichinho que está coçando" (M.F.P., 73 anos).

"Tem que fazer alguma coisa, não passar nada, como vai curar? Água e sabão é para lavar a roupa" (A.S., 67 anos).

Os discursos apresentados demonstram como estes idosos utilizam-se do saber popular, empregam substâncias contra-indicadas pel o saber profissional, trazem nos discursos argumentos bastante simplistas, ausência do pensar imbuído de jul gamento para a situação.

Os elementos que fazem parte do saber popular são legitimados apenas por terem contribuído positivamente para a evolução da ferida cirúrgica, demonstrando que 0 sistema de conhecimento do idoso é construído por meio das suas experiências diárias e das compartilhadas pelas pessoas com as quais convive.

\section{TEMA CULTURAL}

\section{"O CUIDADO DE SI DO IDOSO: AS TEIAS DE SIGNI- FICADOS QUE ELE MESM O TECEU"}

Parafraseando ${ }^{(5: 15)} 0$ homem é um animal amarrado a teias de significados que ele mesmo teceu. A ssumimos 0 título deste tema por acreditarmos que "as teias de significados", assim como para o autor, significam a cultura do ser humano. Este estudo revel ou que o idoso desenvolve 0 cuidado de si preso "as teias de significados" que estes representam nos pequenos detal hes da vida cotidiana.

0 idoso, bem como todo ser humano, utiliza símbolos para a elaboração dos acontecimentos por meio dos quais ele vive, para a orientação no curso das experiências. Sua vida é carregada de simbologias impostas a cada acontecimento pelo qual ele passa. 0 homem necessita de fontes simbólicas para encontrar apoios, utiliza-os para construção dos acontecimentos através dos quais se vive. Os sím- bolos transformam os idosos em seres capazes de pensar, escolher, controlar o eu e, em última análise, romper com os controles socializadores.

Os símbolos são pal avras, atos e objetos usados pelos idosos para comunicar e representar; são atos "com sentido," ou seja, representam algumas coisas para eles. Os recursos simbólicos por meio dos quais os idosos se vêem como pessoas, atores, sofredores, conhecedores e juízes são recursos portadores de significados e doadores de sentido.

Os símbolos são usados

para impor um significado para a experiência. Os indivíduos os encontram em uso corrente na comunidade (Ihe são dados) quando nascem e permanecem em circulação até sua morte. Enquanto vivem se utilizam deles... ${ }^{\text {(5:57). }}$.

A utilização dos símbolos tem o propósito de orientar as experiências que estão sendo vividas. A Igumas vezes são utilizados como forma de al iviar o sofrimento ou como um meio de proteção para as concepções de vida que a pessoa já possui e não pretende reformular.

As pessoas possuem um sistema simbólico constituído de signos ou significados, que foi construído ao longo de sua vida de acordo com a cultura na qual está inserido. Os sistemas simbólicos que os indivíduos usam para construir significados são sistemas já colocados, já estão presentes profundamente arraigados na cultura de cada indivíduo ${ }^{(5)}$.

Dizer que os seres humanos são usuários de símbolos boa parte do tempo não implica negar todas as outras maneiras pelas quais nos comunicamos, mas isolar uma qualidade humana importantíssi ma e examinar sua utilidade para nós profissionais da saúde.

Os símbolos são criados entre as pessoas na interação. Eles são sociais e não instintivos. Recebem um sentido em razão do contexto e esse sentido não é fixo na natureza. Os símbolos são compartil hados entre as pessoas e tudo o que elas decidem tornar um símbolo passa a ser um.

A sociedade humana requer a socialização vitalícia e isso requer o uso de símbolos. Tudo o que é cultural valores, objetos, normas e verdades - é simbólico. Toda a acumulação de conhecimentos passada de uma geração a outra depende da social ização por símbolos. Portanto, os símbol os são a base do pensamento humano e o pensamento, por sua vez, éfundamental para o que fazemos nas situações.

\section{Os símbolos}

são as coisas que os indivíduos usam para se comunicar (inclusive para comunicar-se com 0 eu); eu é o objeto com que 0 indivíduo se comunica (por meio de símbolos); e mente é toda a ação (com símbolos) que praticamos em relação ao eu (22:193-4). 
Para descobrir como os idosos se cuidam, como pensam em se cuidar e com que final idades se cuidam, foi necessário adqui rir familiaridade operacional com os conjuntos de significados em meio aos quais el es levam suas vidas. Isso não requer sentir como eles ou pensar como eles, o que é simplesmente impossível. Requer aprender como viver como eles, sendo de outro lugar e tendo um mundo próprio diferente.

No grupo de idosos encontramos modos de cuidarse mais característicos das camadas populares, porém temos noção de que existe certa margem de liberdade para a compreensão da sociedade complexa, onde os indivíduos participam de forma desigual em diferentes mundos com produção simbólica de alguma especificidade e, em certos casos, até conflitantes.

0 grupo de idosos do estudo apresenta manei ras específicas de estar no mundo, porquanto maneiras próprias de se cuidar. Em parte por se tratar de idosos de baixo nível de escolaridade, o sistema de conhecimento que predomina quanto ao cuidado de si, o qual conseguimos desencavar, num sentido amplo, são nuanças simbólicas de variados matizes, entrel açadas ao sistema de conhecimento popular, advindas do senso comum.

Quando os idosos encontram-se hospitalizados ou no período pós-cirúrgico domiciliar, os mesmos impõem significados a respeito da situação que estão vivenciando. $N$ o período de internação, os idosos recorrem a atividades de lazer que, além de distrair, são formas de entretenimento que os fazem enfrentar de maneira mais rápida e menos sofrida a situação de internamento. Por meio das práticas de distração realizadas no hospital, os idosos estão cuidando de si durante este período, 0 que determina duplicidade funcional destas atividades, tanto como abreviário do tempo, como cuidados pré e pós-cirúrgico.

Durante 0 evento da hospitalização e longe de seu domicílio, o idoso tenta aproximar-se deste ambiente no qual se sente confortável, constrói e mantém objetos que fazem parte de seu mundo no domicílio. Os significantes de cuidado de si são mais evidenciados, principalmente aqueles advindos das práticas populares por se encontrar em seu domicilio livre da "supervisão" dos profissionais de saúde. 0 sistema familiar ou popular é o sistema que mais se envolve no contexto da doença e do cuidado de si.

Nós profissionais da área de saúde, durante nosso cotidiano também empregamos símbolos para nos comunicar, mas os idosos nem sempre nos escutam. Queremos dizer al guma coisa com nossos símbolos, mas os idosos pensam que queremos dizer outra. Os símbolos nem sempre são partilhados com perfeição e com frequêencia existe a possibilidade de um mal entendido, assim como, durante as orientações de cuidados, impositivos, especificamente aqueles que não fazem parte do sistema de significados do idoso, serão pouco absorvidos e muitas vezes não realizados.

0 homem não vive num universo puramente físico, mas num universo simbólico [...] são vários os fios que tecem a rede simbólica, a teia emaranhada da experiência humana ${ }^{(23: 48)}$.

Os simbolismos, que o grupo de idosos pesquisado utiliza durante o período pós-cirúrgico para o cuidado de si nem sempre está adequado perante o saber profissional, mas para os idosos que se utilizam são legítimos, pois o saber popular não exige explicação, é transmitido por meio da cultura, da sua socialização.

Para a enfermagem, usar símbolos significa que somos solucionadoras de problemas em nosso mundo. É necessário planejarmos nossa ação no casamento das simbologias em vez de apenas reagir aos estímulos provocadores da simbologia do outro. Precisamos organizar uma "massa de detalhes significativos" que se tornem disponíveis para nós para aplicação nas situações de cuidado.

U m esforço extremamente sério, quase severo, de entendimento se faz necessário estabelecer relações, lidar com o conflito entre nossa maneira profissional de ol har as coisas e o modo como o idoso ol ha. "É difícil porque não diz respeito apenas ao conteúdo imediato de relação entre nós, mas ao seu sentido amplo, as suas nuanças simbóli-

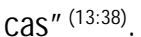

A inda temos confusas esperanças nas possibilidades de progresso com o idoso nas orientações de cuidados, porém são expectativas crescentes se ol harmos com mais clareza no que os idosos estão engajados no cuidado de si. Temos um desejo ardente de que nossas orientações de cuidados não sejam somente impositivas, porquanto, que elas se tornem valiosas para os idosos.

\section{CONSIDERAÇÕES FINAIS}

0 estudo investigou um grupo bastante homogêneo, que apresentava características semel hantes assim como: faixa etária, nível de escolaridade, carência financeira, hospitalização e cirurgia recente. M esmo assim, o mapa social do cuidado de si dos idosos que emergiu está longe de apresentar clareza absoluta.

$M$ ais do que nunca podemos afirmar que os idosos investigados em suas biografias interpretam, mudam com dificuldade e criam símbolos e significados evidentemente vinculados a uma herança, a um sistema de crenças. Os idosos desempenham também papel de agentes na transformação e mudança da cultura de orientações de cuidados, não são meros joguetes de forças impessoais para aquelas advindas do saber profissional. 0 fato de que as pessoas nascem inseridas num sistema sócio-cultural já dado não quer dizer que este sistema não esteja sempre se fazendo 
através das biografias individuais.

Precisamos apreender os códigos (simbolismos) do cuidado de si da cultura popular dos idosos, no mínimo é preciso identificar quais relações podem existir e realizar decodificações necessárias para que as ações de orientações de cuidado não sejam de dominância, mas de coexistência.

Por entendermos neste estudo a cultura como um código, como um sistema de comunicação, assim como "um sistema ordenado de significados e de símbolos" [...] "nos termos dos quais os indivíduos definem seu mundo, expressam seus sentimentos efazem seus jul gamentos" (5:81), percebemos o seu caráter dinâmico ao produzir interpretações, significados, símbolos diante de uma realidade que muda em si. Na perspectiva do idoso a cultura pouco muda, em função da importância para ele das relações de parentesco e religião, sua referência primei ra como sistema de conhecimento.

A creditamos que os resultados desta pesquisa poderiam ser diferentes em uma população de idosos com mel hores recursos financeiros e níveis de escolaridade. Os sistemas simbólicos que estes utilizam para construir significados de cuidados de si estão presentes e são influenciados também pela classe sócio-econômica da qual pertencem.

Como membros de uma sociedade, lidamos com situações e pessoas com as quais podemos estar acostumados, habituados, mas isso não significa que saibamos, conheçamos as experiências de cuidado e não cuidado. Portanto, a possibilidade de procurarmos realizar decodificações dos cuidados de si dos idosos, por mais que envolvam dificuldades, parece ser uma etapa inevitável do desenvolvimento das orientações de cuidado.

Do exposto acima, consideramos que é preciso estabelecer meios efetivos de prover o cuidado de si do idoso, porquanto a noção de distância entre o cuidado profissional e o cuidado de si realizado pelo idoso é problemática e deve ser examinada com cuidado.

A BSTRACT: A n ethnographic study about the elders' selfcare in a surgical unit and at their homes. Field data were collected from A ugust/2002 until M arch/2003, founded on Spradley's participant observation and ethnographic interview. The aim of this study was to get to know how elderly surgical patients deliver self-care during the hospitalization in a surgical unit and at home after discharge. There were (5) identified domains. The theme evol ved from the ethnographic description was: the elders' self-care, the meaning cobwebs that they weaved.

KEY WORDS: Nursing care; A ged; Care; Culture.

RESUM EN: Estudio etnográfico acerca del cuidado de sí mismo de los ancianos en una unidad de internación cirúrgica y en el domicilio. Las informaciones fueron reunidas de agosto de 2002 a marzo de 2003, por medio de la observación participante y de entrevistas etnográficas y fundamentadas en Spradley. El objeto de este estudio fue: conocer como el enfermo anciano cirúrgico hace el cuidado de sí mismo durante la internación en una unidad cirúrgica en el posoperatorio domiciliar. Los dominios identificados fueron cinco. El tema que ha emergido de la descripción etnográfica: el cuidado del anciano de sí mismo, tela de significados que él mismo ha tejido.

PALABRAS CLAVE: A tención de enfermería; A nciano; Cuidado; Cultura.

\section{REFERÊNCIAS}

1. IPA RDES. Sistema Estadual de informações. Curitiba; 2005.

2. IBGE. Censo Demográfico de 2000. Disponível em: www.ibge.gov.br

3. Palloni $A$, Peláez M. Histórico e natureza do estudo. In: Lebrão $M$, Duarte YA O. SABE - Saúde, bem-estar e envelhecimento. Brasília: Organização Pan-A mericana da Saúde; 2003.

4. Cesar CL G, Paschoal SM P. U so dos serviços de saúde. In: L ebrão ML, Duarte YA . O. SA BE - Saúde, bem-estar e envelhecimento. B rasília: Organização Pan-A mericana da Saúde; 2003.

5. Geertz C. A interpretação das culturas. Rio de Janeiro: LTC; 1989.

6. Eliade M. M ito e realidade. São Paulo:Perspectiva; 1991.

7. Ministério da Justiça (BR). Secretaria Nacional dos Direitos Humanos. Política Nacional do Idoso. Programa Nacional de Direitos Humanos. B rasília;1998.

8. Spradley JP, M CCurdy DW. The cultural experience: etnography in complex society. Chicago: SRA; 1972.

9. Sradley JP. The etnographic interview. New York: Holt, Rinehart and Winston; 1979

10. _._. Participant observation. O rlando: Holt, Rinehart and Winston; 1980.

11. Geertz C. Works and lives: the anthropologist as author. Stanford: Stanford University Press; 1988.

12. 0 saber local: novos ensaios em antropologia interpretativa. Petrópolis: Vozes; 1997

13. $\overline{200 \overline{1} .}$. Nova luz sobre a antropologia. Rio de Janeiro: Jorge Zahar;

14. M inistério da Saúde (BR). Conselho Nacional deSaúde, Comitê Nacional de Ética em Pesquisa em Seres Humanos. Resolução 196 de outubro de 1996: diretrizes e normas regulamentadoras de pesquisa envolvendo seres humanos. Brasília (DF); 1996.

15. Helman CG. Cultura, saúde e doença. Porto A legre: A rtes M édicas; 1994. 
16. Dumazedier J . Lazer e cultura popular. 3.ed. São Paulo: Perspectiva; 2000.

17. Papaléo N etto M . A velhice e o envelhecimento em visão globalizada. São Paulo: A theneu; 1996.

18. Lenardt MH, Kami MT, B rey $C$. Insuficiência súbita de controle postural no idoso: prática assistencial numa abordagem investigativa. Cogitare Enferm 2001; 6(1):90-6.

19. K leinman A. Patients and healers in the context of culture. B erkeley: University of California; 1980.

20. Gonçalves L H. Takase. Ser ou estar saudável na velhice. Florianópolis. Texto Contexto Enferm 1992; 1(2):100-13.

21. Rabelo M CM. Religião, ritual e cura. In: Alves PC, M inayo M CS. Saúde e doença: um olhar antropológico. Rio de Janeiro: Fiocruz; 1994.

22. Charon JM . Sociologia. São Paulo: Saraiva; 1999.

23. Casirer E. Ensaio sobre o homem. São Paulo: M artins Fontes; 2001.

ENDEREÇO DOSAUTORES:

Rua Comendador Fontana, 50 - ap. 44

Curitiba-PR

80030-070

lenardthart@ hotmail.com 